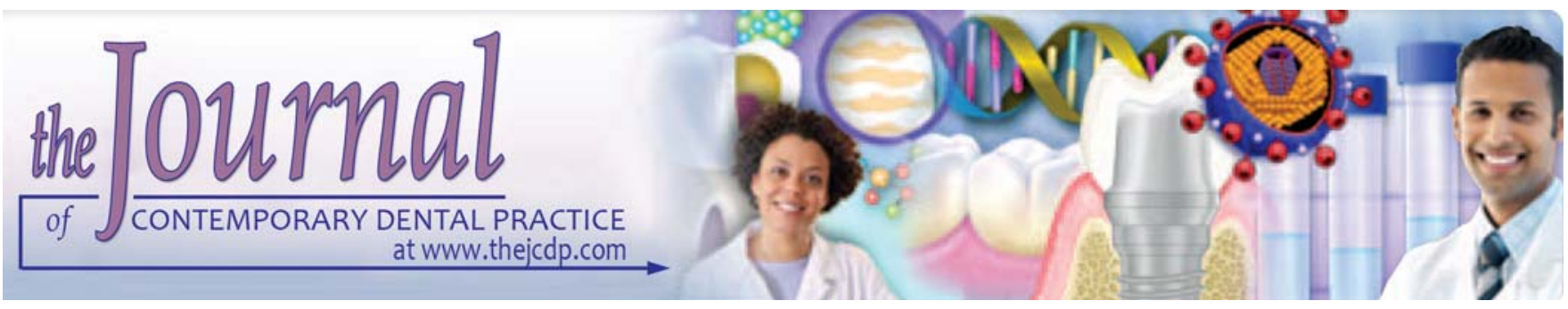

\title{
Comparison of Chemical Aging and Water Immersion Time on Durability of Resin-Dentin Interface produced by an Etch-and-Rinse Adhesive
}

Bruna Uglik Garbui, Sergio Brossi Botta, Andre Figueiredo Reis, Adriana Bona Matos

\begin{abstract}
Aim: The aim of this study was to analyze and compare the influence of short-term $\mathrm{NaOCl}$-storage and long-term water storage on the microtensile bond strength ( $\mu$ TBS) of etch-andrinse adhesive system to human dentin.
\end{abstract}

Materials and methods: Thirty-six third human molars were randomly divided into 6 groups $(n=6)$ according to the aging protocol: G 1 (water, 24 hours); G2 (water, 6 months); G 3 (water, 12 months); $\mathrm{G} 4$ (10\% sodium hypochlorite - $\mathrm{NaOCl}, 1$ hour); G5 $(10 \% \mathrm{NaOCl}, 3$ hours) and $\mathrm{G} 6(10 \% \mathrm{NaOCl}, 5$ hours). A two-step etch-and-rinse adhesive (Adper Single Bond 2) was applied according to the manufacturers' instructions. A composite ( $F$ iltek Z250) was applied in four horizontal increments and was individually cured. S pecimens were cut following the microtensile test technique, submitted to the different aging protocols, and tested in tension. The fracture pattern was observed in a stereomicroscope (40x magnification) and in a scanning electron microscope. The $\mu$ TBS data were analyzed by ANOVA and Tukey's test $(\alpha=0.05)$.

Results: The effect of storage in $10 \% \mathrm{NaOCI}$ for 1 or 3 hours was not significantly different from that of aging in distilled water (DW) for 6 or 12 months ( $p>0.05$ ). Beams immersed in DW for 24 hours and in $10 \% \mathrm{NaOCl}$ for 5 hours showed the highest and lowest $\mu$ TBS values respectively.

Conclusion: The aging protocols negatively influenced dentin bond strength. Aging specimens in $10 \% \mathrm{NaOCI}$ for 1 or 3 hours can be an alternative method for long-term water storage ( 6 or 12 months) bond strength studies.

Clinical significance: This aging protocol allows a quick achievement of longitudinal bond strength data, so that results are available to the professionals in this area while the materials are yet present at the dental market.

Keywords: Laboratory research, Dental adhesive, Adhesion, Collagen, Dentin, Degradation, Durability, Microtensile bond test, Sodium hypochlorite.

How to cite this article: Garbui BU, Botta SB, Reis AF, Matos $A B$. C omparison of Chemical Aging and Water Immersion Time on Durability of Resin-Dentin Interface produced by an Etchand-R inse Adhesive. J Contemp DentP ract 2012;13(4):464-471.

\section{Source of support: Nil}

\section{Conflict of interest: None declared}

\section{INTRODUCTION}

The current approach of operative dentistry is focused on conservative restorative procedures. This is possible due to improvement of restorative techniques and polymeric materials for dental applications. However, hybrid layer degradation overtime is still a major issue. ${ }^{1-6}$ Thus, replacement of adhesive restorations are normal ly necessary, leading to the so-called restorative cycle, where restorations are replaced by larger and more complex ones, compromising resistance of dental structure. ${ }^{7}$

Etch-and-rinse systems show excellent performance in dentin bond strength tests when short-term bond strength is evaluated (24 hours). ${ }^{3,4,8-11}$ However, reduction in bond strength values is normally observed in long-term evaluations (6 months or more). ${ }^{3,9-12}$ This reduction in restoration durability occurs due to hydrolysis of resin and/ or collagen fibrils, ${ }^{3,4}$ which causes degradation of the hybrid layer. $1,2,6,12,13$

W ater storage is the most used procedure for specimen aging in durability tests of dentin-resin interfaces. ${ }^{14-18}$ However, this method requires an idle period until results are obtained, and it is likely that the product under test becomes obsolete or out of the dental market. Thus, comparative studies of methods able to shorten this idle time are necessary and welcome.

Storage of specimens in 10\% sodium hypochlorite $(\mathrm{NaOCl})$ has been proposed with the intent to reduce experimental time. ${ }^{14-18}$ Researchers ${ }^{14-16}$ confirmed a higher reduction in bond strength (BS) and an increase in nanoleakage ${ }^{14}$ for etch-and-rinse adhesive systems. However, the protocol for specimen aging with $10 \% \mathrm{NaOCl}$ 
is not yet standardized in the literature. A uthors use different $\mathrm{NaOCI}$ immersion times, e.g. 2, 4, 5 or 6 hours. ${ }^{18}$ Establishment of a standardized technique in order to compare results is essential. Tests of new formulations for dentin adhesives or new substrate treatments would be another important application, in which accelerated aging (within a few hours) could help to predict the long-term bond strength performance. Thus, storage in $10 \% \mathrm{NaOCl}$ solution has shown to be a fast and reliable method for durability tests of the adhesive interface. However, the immersion time in this solution has not been defined so far.

Therefore, the aim of this study was to compare the influence of different specimen aging protocols on the BS of an etch-and-rinse adhesive system.

\section{MATERIALS AND METHODS}

\section{Teeth Selection and Preparation}

Thirty-six recently extracted human third molars $(n=6)$ stored for no more than 90 days in distilled water at $4^{\circ} \mathrm{C}$ were used in the present study. The occlusal surface was flattened with silicon carbide paper $(240,320$ and 400) and a polishing device (100 rpm) with abundant water refrigeration. A standard smear layer was created \#600 SiC paper (60 seconds) before adhesive procedures.

\section{Adhesive and Restorative Procedures}

A two-step etch-and-rinse adhesive system (A dper Single Bond 2, 3M ESPE, St Paul, M N , EUA ) was used according to the manufacturer' s instructions (Table 1 ). A fter adhesive photo activation (A stralis 3 - Ivoclar Vivadent, A mherst, $\mathrm{NY}, \mathrm{EUA} ; 600 \mathrm{~mW} / \mathrm{cm}^{2}$ ), a composite resin (Filtek Z250, $3 M$ ESPE) 'crown' was built in 4 horizontals increments $(4 \times 1 \mathrm{~mm})$, which were cured (20 s) individually using the same light-curing unit.

Restored teeth were stored in distilled water at $37^{\circ} \mathrm{C}$ for 24 hours. Beams were obtained with a cross-sectional bonded area of approximately $0.9 \mathrm{~mm}^{2}$ with a highconcentration diamond disk (Buehler Ltd. Lake Bluff, Illinois, EUA) under abundant water refrigeration, coupled with a precision cutting device (I somet 1000, B uehler L td., Lake Bluff, IL, EUA - Proc FA PESP 05/04701-7). The beams were evaluated laterally under a light microscope (30x magnification) to check the adhesion area for failures. The specimens with visually detected defects on the adhesive interface were discarded.

\section{Aging Protocol}

Beams were randomly divided into 6 groups $(n=6)$, according to the aging protocol: $\mathrm{G} 1$ (water storage for 24 hours), G2 (water storage for 6 months), G3 (water storage for 12 months), $\mathrm{G} 4(10 \% \mathrm{NaOCl}$ storage for 1 hour), G5 ( $10 \% \mathrm{NaOCl}$ storage for 3 hours) and $\mathrm{G} 6(10 \% \mathrm{NaOCl}$ storage for 5 hours).

A fter storage, specimens were individually fixed by their ends with a cyanoacrylate ester-based gel adhesive (Super B onder- L octite Brasil Ltd., Itapevi, SP, B razil), to a jig attached to a U niversal Testing M achine (EZ-Test 500N, Shimadzu Co, Kyoto, Japan) and tested in tension at a crosshead speed of $1 \mathrm{~mm} / \mathrm{min}$.

A fter the microtensile test, fractured specimens were mounted on metallic stubs and sputter-coated with gold (Denton Desk II, Denton V acuum, LL C, M oorestown, N) , EUA).

\section{Failure Mode Evaluation}

W e examined fractured specimens using a stereomicroscope (M iview Digital M icroscope Cosview Technologies Co. Ltd., Bantian, Longgang Dist, China) at 200x magnification to determine the mode of failure. Failure modes were classified as adhesive, cohesive failure of substrate, cohesive failure of restorative material or mixed (failures that involved adhesive interface and cohesive failure in substrate or adhesive interface and cohesive failure in restorative material).

For illustration of the fracture pattern, 12 representative specimens of each group were maintained for 48 hours in a desiccator (Sample Dry K eeper Simulate Corp, Tokyo, Japan) and then mounted on aluminum stubs with carbon cement. They were then sputter-coated with pure gold by means of a sputter-coating Denton D esk II (Denton V acuum, LLC, M oorestown, NJ , USA ) and observed with a scanning electron microscopy (SEM - JEOL JSM 6460, LV, J eol Ltd., Tokyo, Japan, FA PESP \# 00/08231-1) using acceleration voltage: $15 \mathrm{kV}$; working distance: $30 \mathrm{~mm}$; spot size: $28 \mathrm{~mm}$, so that microscopic fracture patterns and the morphology of the debonded interface could be studied.

Table 1: Adhesive system: Composition and application mode

\begin{tabular}{lll}
\hline Adhesive system & Composition & Application mode \\
\hline Adper Single Bond 2 & Bis-GMA, HEMA, dimethacrylates, & 1. Apply etchant for 15 seconds on dentin/enamel surface \\
(3M ESPE, St Paul, & methacrylate functional copolymer & 2. R inse with water for 30 seconds \\
MN, USA) & of polyacrylic and polyitaconic acids, & 3. Blot-dry dentin with a filter paper leaving it visibly moist \\
& ethanol, water, silica nanofillers, & 4. Apply adhesive on enamel/dentin surface \\
& photoinitiators & 5. Gently air-dry for 10 seconds at a distance of $10 \mathrm{~cm}$
\end{tabular}


Photomicrographs were obtained for beam visualization (90x magnification) and fracture classification, and the most representative region of each surface was analyzed $(1,000 x$ magnification).

\section{STATISTICAL ANALYSIS}

Data were analyzed by one-way analysis of variance (A N OVA) and Tukey's test. The confidence level was set at $\alpha=0.05$.

\section{RESULTS}

\section{Microtensile Bond Strength}

Mean values for the microtensile bond strength ( $\mu T B S$ ), standard deviation (SD) and number of pretest failures for each group are presented in Table 2, when analyzed by the A NOV A and Tukey's test. Tukey test showed statistically significant differences among groups $(p<0.05)$. It was possible to observe that water storage for 24 hours (group 1) showed the highest $\mu$ TBS values. W ater storage for 6 or 12 months or in $\mathrm{NaOCl}$ storage for 1 or 3 hours showed no statistical difference between them. On the other hand, storage in $\mathrm{NaOCI}$ for 5 hours showed the lowest $\mu$ TBS values.

\begin{tabular}{lcccc} 
Table 2: Mean $( \pm \mathrm{SD})$ & values for the $\mu$ TBS test and number of \\
pretest failures & & \\
\hline Groups & MPa & $\pm S D$ & $\begin{array}{c}\text { Valid } \\
\text { beams }\end{array}$ & $\begin{array}{c}\text { Beams } \\
\text { lost }\end{array}$ \\
\hline G1-24 hours $\left(\mathrm{H}_{2} \mathrm{O}\right)$ & $54.9 \mathrm{a}$ & 8.3 & 100 & 1 \\
G2-6 months $\left(\mathrm{H}_{2} \mathrm{O}\right)$ & $34.2 \mathrm{~b}$ & 7.9 & 100 & 2 \\
G3-12 months $\left(\mathrm{H}_{2} \mathrm{O}\right)$ & $32.0 \mathrm{~b}$ & 3.4 & 99 & 10 \\
G4-1 hours $(\mathrm{NaOCl})$ & $27.8 \mathrm{~b}$ & 4.4 & 94 & 3 \\
G5-3 hours $(\mathrm{NaOCl})$ & $32.4 \mathrm{~b}$ & 3.0 & 99 & 4 \\
G6-5 hours $(\mathrm{NaOCl})$ & $14.0 \mathrm{C}$ & 2.3 & 83 & 14 \\
\hline
\end{tabular}

\section{Stereomicroscopic Observation of Failure Modes}

Figure 1 shows results for failure mode evaluation. A ll tested groups exhibited mainly adhesive/mixed fractures. The beams stored in water for 24 hours exhibited adhesive/mixed fractures (ca. $85 \%$ ). B eams stored in water for 6 or 12 months exhibited predominantly adhesive/mixed fractures (ca. $80 \%$ ). On the other hand, groups aged in $\mathrm{NaOCl}$ for 1 or 3 hours exhibited mostly adhesive/mixed fractures (ca. $70 \%$ ) and about $15 \%$ dentin cohesive failure. Groups immersed in $\mathrm{NaOCl}$ for 5 hours exhibited about $50 \%$ adhesive/mixed fractures and $25 \%$ dentin cohesive fractures, and a significant number of pretest failures (14 beams) indicating weakening of specimens. Groups that were subjected to the $\mathrm{NaOCl}$ aging protocol exhibited higher number of dentin cohesive fractures than other groups.

In general, beams degraded from the periphery toward the center of the specimens regardless of the aging protocol.

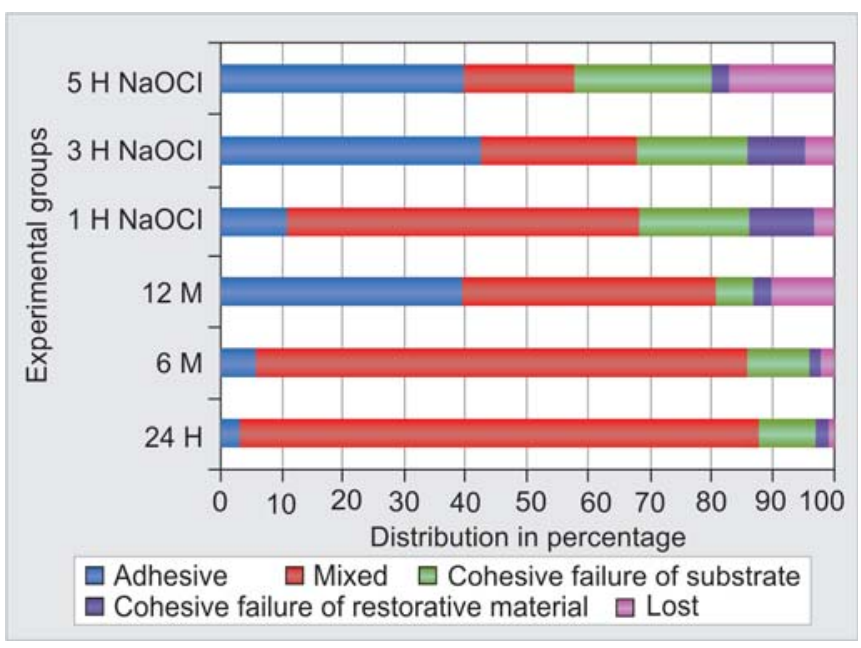

Fig. 1: Distribution of failure modes on test groups obtained with different protocols

\section{Scanning Electron Microscope Observations}

The effect of water storage for 24 hours can be observed in Figure $2 \mathrm{~A}$, where fracture occurred at the base of the hybrid layer. A flat surface, open dentin tubules, and a few tubules with resin tags inside them can be identified (Fig. 2B).

When specimens were submitted to water storage for 6 months the occurrence of mixed fracture with adhesivecovered areas in the center of the specimen (Fig. 2C) and areas with fracture at the base of the hybrid layer due to the presence of dentin tubules with resin tags inside them (Fig. 2D) can be observed.

A fter water storage for 12 months specimens showed mixed fracture where adhesive-covered areas can be observed at the center of the specimen (Fig. 2E). O pen dentin tubules without presence of remaining resin tags can be observed at the periphery of the specimens (Fig. $2 F$ ).

Storage under $10 \% \mathrm{NaOCl}$ for 1 hour caused mixed fracture with adhesive-covered areas at the center of the specimens (Fig. 3A) and with dentin tubules filled with resin tags on the left side (Fig.3B). At the periphery of the specimens fracture of the hybrid layer base can be identified due to the presence of open dentin tubules.

The effect of storage in $10 \% \mathrm{NaOCI}$ for 3 hours can be seen where a mixed fracture with adhesive-covered areas can be observed at the center of the specimens (Fig. 3C) with a lower extent compared to Fig. 3A. On the periphery of the specimens, fracture at the base of the hybrid layer with open dentin tubules (Fig. 3D) can be observed.

However, when the storage in $10 \% \mathrm{NaOCl}$ was performed for 5 hours, mixed fracture can be observed with an adhesive-covered small region at the center of the specimen (Fig. 3E) and some regions clearly showed that the entire hybrid layer was dissolved. In addition, the dentin tubules were greatly enlarged (Fig. 3F). 

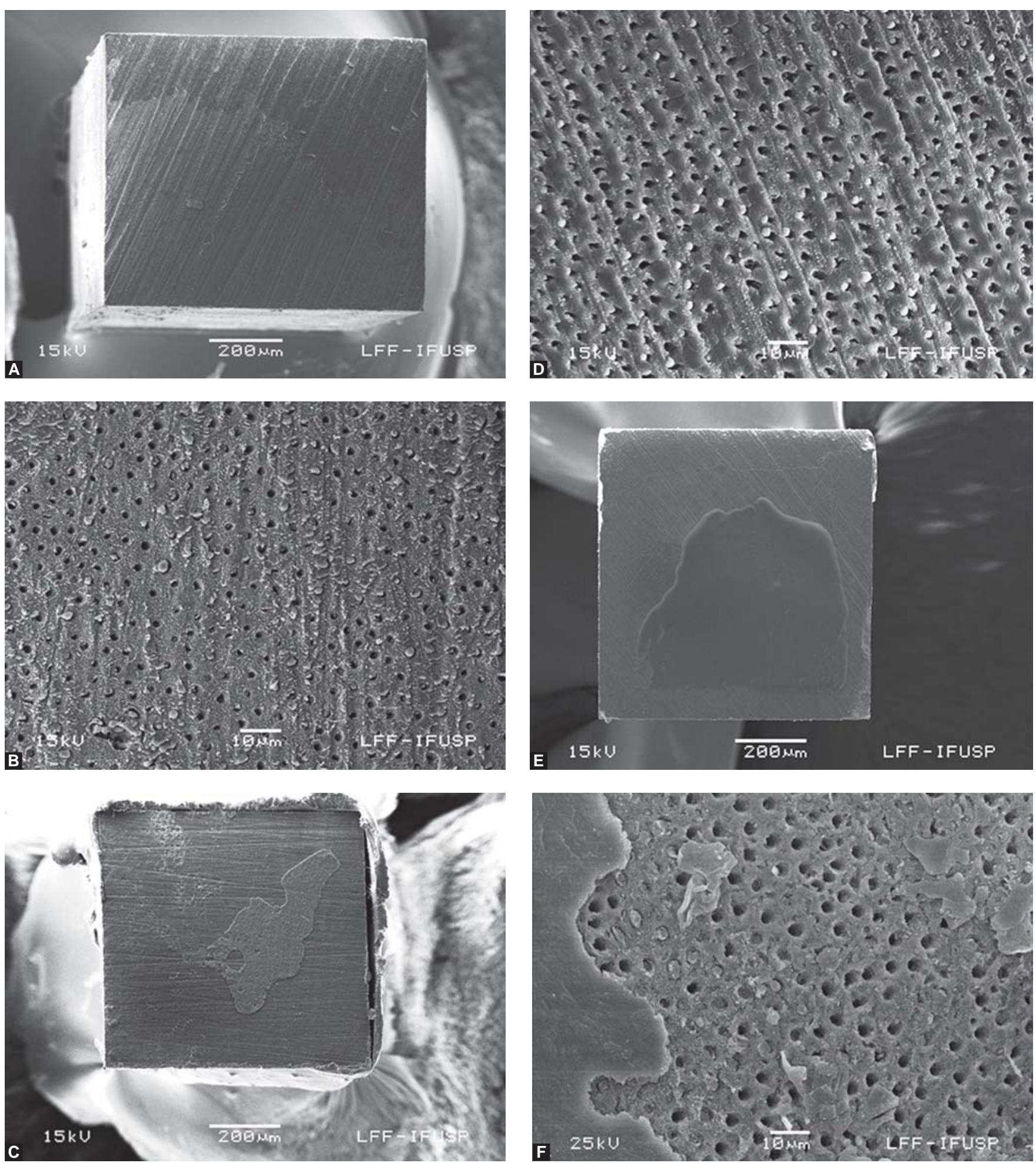

Figs 2A to F: SEM photomicrographs of the failure pattern of $\mu$ TBS beams submitted to water storage: (A) The effect of water storage for 24 hours can be observed $(\times 90)$; $(B)$ higher magnification of $A(\times 1,000)$ showed that fracture occurred at the base of the hybrid layer with open dentinal tubules all over the dentinal surface; (C) when beams were stored for 6 months $(\times 90)$, mixed fracture at the base of the hybrid layer can be seen with adhesive-covered areas in the center of the specimen and areas, it can also be identified a centripetal degradation of the adhesive interface; (D) due to the presence of dentin tubules with resin tags inside them, it can be assumed that fracture occurred at the base of the hybrid layer $(\times 1,000)$; $(E)$ after water storage for 12 months specimens $(\times 90)$, the same centripetal pattern of degradation occurred with the occurrence of mixed fracture, where adhesive-covered areas can be observed at the center of the specimen; $(F)$ open wide dentinal tubules without presence of remaining resin tags $(\times 1,000)$ 

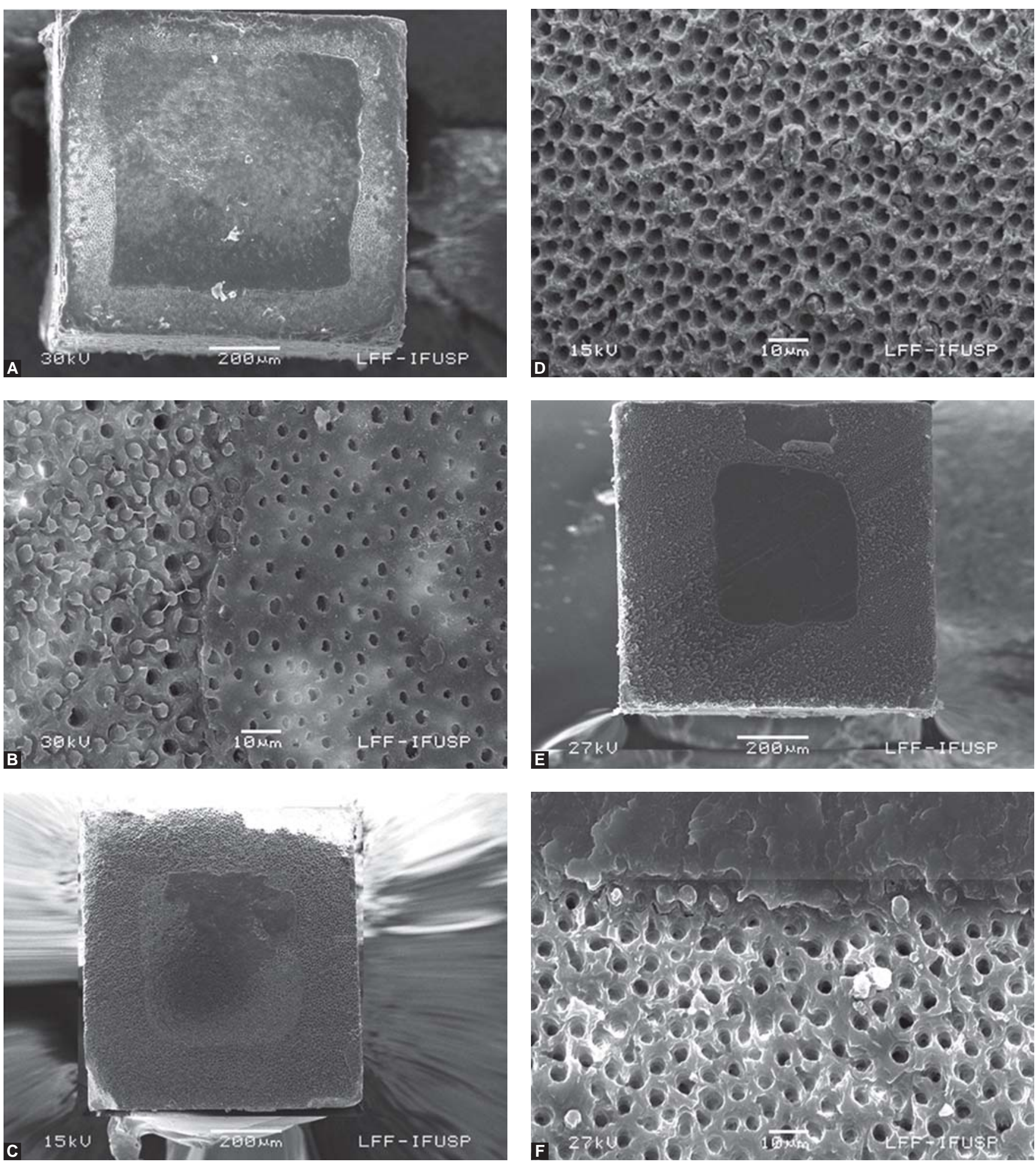

Figs 3A to F: SEM photomicrographs of the failure pattern of $\mu$ TBS beams submitted to sodium hypochlorite storage: (A) Storage in $10 \%$ $\mathrm{NaOCl}$ for 1 hours caused mixed fracture with adhesive-covered areas at the center of the specimens $(\times 90)$; (B) in higher magnification of $A(\times 1,000)$, a surface with dentin tubules filled with resin tags at the periphery of the specimens as well as regions with fracture of the hybrid layer base due to the presence of open dentin tubules; $(C)$ after 3 hours of $10 \% \mathrm{NaOCl}$ storage, a larger centripetal degradation could be observed when compared to the effect in $A$, a mixed fracture with adhesive-covered areas can be observed at the center of the specimens; $(D)$ in higher magnification $(\times 1,000)$ in the periphery of the specimens, fracture at the base of the hybrid layer with open dentin tubules can be observed; $(E)$ however, when the storage in $10 \% \mathrm{NaOCl}$ was performed for 5 hours, mixed fracture $(\times 90)$ can be observed with an small region covered by adhesive at the center of the specimen and some regions clearly showed that the entire hybrid layer was dissolved; $(F)$ in this higher magnification of $E(\times 1,000)$, adhesive interface were intensively degraded with dentin tubules greatly enlarged by the deproteinizing effect of the $\mathrm{NaOCl}$ 
Comparison of Chemical Aging and Water Immersion Time on Durability of R esin-Dentin Interface

\section{DISCUSSION}

Although water storage and thermocycling are established techniques for aging of the adhesive interface, both methods require long experimental periods. ${ }^{14}$ Due to this limitation, aging of adhesive interfaces using $10 \% \mathrm{NaOCl}$ solution has been proposed because it provides results more rapidly. ${ }^{14-16,18-21}$

$\mathrm{NaOCl}$ is a nonspecific deproteinizing agent that in aqueous solution forms superoxide radicals $\left(\mathrm{O}_{2}^{-}\right)$, which induce peptide chain oxidation in proteins, such as collagen. ${ }^{22}$ This solution can also cause chlorination of the $\mathrm{N}$-terminal end of proteins and formation of hypochlorous acid. ${ }^{23}$ Some of these chloramines are associated with an increase in the susceptibility of collagen fibrils degradation. ${ }^{24}$

This degradation potential of $\mathrm{NaOCl}$ solution is responsible for the effective removal of organic compounds from the resin/dentin interface. This is due to its ability to dissolve the collagen fibrils that were not encapsulated by the adhesive resin, ${ }^{18,19}$ thus, generating a higher degradation of the bonded interface and lower bond strength values. ${ }^{14,19,20}$

In the present study, bond strength values for specimens stored in distilled water for 24 hours were significantly higher than those of specimens stored in water for 6 months or 1 year, corroborating the results established in the literature. $^{9-12,25}$ The reduction in bond strength values can be explained by chemical hydrolysis of the resin and/or collagen fibrils, since the depth of dentin demineralization resulting from phosphoric acid application usually exceeds the capacity of resin monomer diffusion. ${ }^{3}$ This difference in results is due to the formation of a demineralized resin zone partially infiltrated and without protection at the base of the hybrid layer. ${ }^{26,27}$ As a consequence, partially infiltrated zones occur, ${ }^{28,29}$ which are vulnerable to degradation, ${ }^{30}$ thus, jeopardizing stability of adhesion between resin and dentin.

A s occurred in the groups aged in distilled water, bond strength values observed after aging in $10 \% \mathrm{~N} \mathrm{aOCl}$ solution for 1,3 and 5 hours were lower than those obtained in the control group (specimens tested after 24 hours storage in water), ${ }^{14-18,20}$ reinforcing that this is a method for accelerated aging of specimens.

No significant difference was found when bond strength values of groups stored in $10 \% \mathrm{NaOCl}$ for 1 and 3 hours were compared, in accordance with previous investigations. ${ }^{15}$ However, it was observed that $\mu$ TBS values were significantly reduced when specimens were stored in 10\% $\mathrm{NaOCl}$ for 5 hours. A possible explanation for this finding is that the longer the specimen remains in contact with $\mathrm{NaOCl}$ solution, it is able to break peptide chains of collagen fibrils by installing the process of degradation of the adhesive interface. Scanning electron microscope (SEM) observation demonstrated that the entire hybrid layer was clearly dissolved in some regions after aging in $\mathrm{NaO} C$ for 5 hours. In addition, dentin tubules were greatly enlarged. The higher number pretesting failures in this group can be related to the weakening of the underlying dentin.

When bond strength values of groups stored in water and in $\mathrm{NaOCl}$ solution were compared, it was found that $\mu$ TBS of specimens stored in water for 6 and 12 months were similar to those aged in $10 \% \mathrm{NaOCl}$ solution for 1 hours or 3 hours. Studies comparing aging in $10 \% \mathrm{NaOCl}$ for 3 hours and in distilled water for 6 or 12 months were not found in the literature. The most similar study available compared aging in $10 \% \mathrm{NaOCl}$ for 3 hours and storage in artificial saliva for 6 months ${ }^{14}$ and the results shown therein are similar to those found in our study.

In bond strength mechanical tests, fractured specimen surfaces generate information on the fracture mechanism. This type of analysis is important to verify, if the test was conducted adequately, inducing tension in order to break the bonded interface and not the adherent or adhered elements. B ond strength tests must induce uniform tension in order that the interface is tested, not the substrate. . $^{31,32}$

In general, a higher amount of mixed and adhesive fractures was detected in this study regardless of the aging protocol used. Beams stored in water for 6 or 12 months and in $10 \% \mathrm{NaOCI}$ for 1,3 and 5 hours degraded specimens from the periphery toward the center thus exhibiting centripetal bond interface degradation as observed in the literature. ${ }^{15,20}$ Degradation was higher in the specimens stored in $\mathrm{NaOCl}$ for 5 hours.

When specimens were stored in $10 \% \mathrm{NaO} \mathrm{Cl}$ for 5 hours, a higher frequency of dentin cohesive failures was verified because $\mathrm{NaOCl}$ can remove dentin organic components increasing its porosity, ${ }^{33}$ causing substrate weakening and, consequently, a higher number of cohesive fractures. Therefore, a 5 hours exposure to $\mathrm{NaOCl}$ can be considered excessive, since, it caused reduction of $\mu$ TBS results but also changes in the substrate. On the other hand, aging in $\mathrm{NaOCl}$ for 1 to 3 hours caused a degradation pattern very similar to that observed with water storage for 6 and 12 months and similar $\mu$ TBS values.

\section{CONCLUSION}

It was concluded that storage of specimens in $10 \% \mathrm{NaOCl}$ solution is valid as an aging protocol with the advantage of allowing us to get, after only 1 to 3 hours, BS data equivalent 
to those of water storage for 6 to 12 months. Clearly, the immersion time in $10 \% \mathrm{NaOCl}$ solution should be chosen by the researcher. Studies with the use of these protocols for accelerated aging of specimens and different adhesive systems are necessary.

\section{CLINICAL SIGNIFICANCE}

This aging protocol allows a quick achievement of longitudinal bond strength data, so that results are available to the professionals in this area while the materials are yet present at the dental market.

\section{ACKNOWLEDGMENT}

The authors acknowledge Dr Paulo Boschcov, former professor at UNIFESP, whose suggestions contributed to improve the quality of the final version of the manuscript.

\section{REFERENCES}

1. Hashimoto M, Ohno H, Kaga M, Endo K, Sano H, Oguchi H. In vivo degradation of resin-dentin bonds in humans over 1 to 3 years. J Dent Res 2000;79(6):1385-91.

2. De M unck J, V an M eerbeek $B, Y$ oshida $Y$, Inoue $S, V$ argas $M$, Suzuki K, et al. Four-year water degradation of total-etch adhesives bonded to dentin. J Dent Res 2003;82(2):136-40.

3. De M unck J, V an Landuyt $K$, Peumans $M$, Poitevin $A$, L ambrechts $P, B$ raem $M, V$ an $M$ eerbeek $B$. A critical review of the durability of adhesion to tooth tissue: $M$ ethods and results. J Dent Res 2005;84(2):118-32.

4. Breschi L, M azzoni A, Ruggeri A, Cadenaro M , Di L enarda R, De Stefano Dorigo E. Dental adhesion review: A ging and stability of the bonded interface. Dent M ater 2008;24(1):90101.

5. Carrilho M RO, Geraldeli S, Tay F, de G oes M F, Carvalho RM , Tjäderhane $L$, et al. In vivo preservation of the hybrid layer by chlorhexidine. J Dent Res 2007;86(6):529-33.

6. Tanaka J, Ishikawa K, Y atani H, Y amashita A, Suzuki K. Correlation of dentin bond durability with water absorption of bonding layer. Dent M ater J 1999;18(1):11-18.

7. Elderton RJ . Changing the course of dental education to meet future requirements. J Can Dent A ssoc 1997;63(8):633-39.

8. Reis AF, Giannini M, Pereira PN R. Influence of water-storage time on the sorption and solubility behavior of current adhesives and primer/adhesive mixtures. O per Dent 2007;32(1): 53-59.

9. Komori PC, Pashley DH, Tjaderhane $L, B$ reschi $L, M$ azzoni $A$, de Goes MF, W ang $L$, et al. Effect of $2 \%$ chlorhexidine digluconate on the bond strength to normal versus caries-affected dentin. Oper Dent 2009;34(2):157-65.

10. Loguercio AD, Stanislawczuk R, Polli LG, Costa JA, Michel $M D, R$ eis A . Influence of chlorhexidine digluconate concentration and application time on resin-dentin bond strength durability. Eur J Oral Sci 2009;117(5):587-96.

11. Skovron L, K ogeo D, Gordillo LAA, M eier M M , Gomes OM M, Reis A, L oguercio AD. Effects of immersion time and frequency of water exchange on durability of etch-and-rinse adhesive. J Biomed M ater Res B : A ppl Biomater 2010;95B (2):339-46.
12. Carrilho MRO, Carvalho RM, de Goes MF, di Hipólito V, Geraldeli S, Tay FR, et al. Chlorhexidine preserves dentin bond in vitro. J Dent Res 2007;86(1):90-94.

13. Hashimoto M. A review-micromorphological evidence of degradation in resin-dentin bonds and potential preventional solutions. J Biomed M ater Res B : A ppl Biomater 2010;92B (1): 268-80.

14. Saboia VPA, Silva FCFA, N ato F, M azzoni A, Cadenaro M, $M$ azzotti $G$, et al. A nalysis of differential artificial aging of the adhesive interface produced by a two-step etch-and-rinse adhesive. Eur J Oral Sci 2009;117(5):618-24.

15. $Y$ amauti $M$, Hashimoto $M$, Sano $H, O$ hno $H, C$ arval ho $R M, K$ aga $\mathrm{M}$, et al. Degradation of resin-dentin bonds using $\mathrm{NaO} \mathrm{Cl}$ storage. Dent $M$ ater 2003;19(5):399-405.

16. $Y$ oshida $E$, Hashimoto $M, H$ ori $M, K$ aga $M$, Sano $H, O$ guchi $H$. Deproteinizing effects on resin- tooth bond structures. J Biomed Mater Res B: A ppl Biomater 2004;68B (1):29-35.

17. Sauro S, Mannocci F, Toledano M, Osorio R, Pashley DH, Watson TF. EDTA or $\mathrm{H}_{3} \mathrm{PO}_{4} / \mathrm{NaOCl}$ dentine treatments may increase hybrid layers' resistance to degradation: A microtensile bond strength and confocal-micropermeability study. J Dent 2009;37(4):279-88.

18. O sorio R, E rhardt M CG, Pimenta LAF, O sorio E, T oledano M . EDTA treatment improves resin-dentin bonds' resistance to degradation. J Biomed M ater Res B: Appl Biomater 2005; 84(8):736-40.

19. Toledano M, Osorio R, Albaladejo A, A guilera FS, Osorio E. Differential effect of in vitro degradation on resin-dentin bonds produced by self-etch versus total-etch adhesives. J Biomed Mater Res Part A 2006;77A (1):128-35.

20. De M unck J, Ermis R B, K oshiro K, Inoue S, Ikeda T, Sano H, et al. $\mathrm{NaOCI}$ degradation of a $\mathrm{HEM} \mathrm{A}$-free all-in-one adhesive bonded to enamel and dentin following two air-blowing techniques. J Dent 2007;35(1):74-83.

21. M onticelli F, Osorio R, Pisani-Proença J, Toledano M. Resistance to degradation of resin-dentin bonds using a onestep HE M A -free adhesive. J D ent 2007;35(2):181-86.

22. Habelitz S, B al ooch M, M arshall SJ, B al ooch G, M arshall GW. In situ atomic force microscopy of partially demineralized human dentin collagen fibrils. J Struct Biol 2002;138(3):227-36.

23. W eiss SJ, K lein R, Slivka A, W ei M. Chlorination of taurine by human neutrophils. Evidence for hypochlorous acid generation. J Clin Invest 1982;70(3):598-607.

24. Olszowski S, M ak P, Olszowska E, M arcinkiewicz J. Collagen type II modification by hypochlorite. Acta Biochim Pol 2003;50(2):471-79.

25. Reis A, L oguercio A D, Carvalho RM , Grande RH M. Durability of resin dentin interfaces: Effects of surface moisture and adhesive solvent component. D ent $M$ ater 2004;20(7):669-76.

26. $W$ ang $Y$, Spencer $P$. A nalysis of acid-treated dentin smear debris and smear layers using confocal Raman microspectroscopy. J Biomed Mater Res B: A ppl Biomater 2002;60(2):300-08.

27. Spencer $P, Y$ e Q, Park J, Topp EM , M isra A, M arangos 0 , et al. Adhesive/Dentin interface: The weak link in the composite restoration. A nn Biomed Eng 2010;38(6):1989-2003.

28. A rmstrong SR, Keller JC, B oyer DB. The influence of water storage and $\mathrm{C}$-factor on the dentin-resin composite microtensile bond strength and debond pathway utilizing a filled and unfilled adhesive resin. Dent M ater 2001;17(3):268-76. 
29. Hashimoto M, Tay FR, O hno H, Sano H, Kaga M, Y iu C, et al. SEM and TEM analysis of water degradation of human dentinal collagen. J Biomed M ater Res B: A ppl Biomater 2003;66B(1): 287-98.

30. Bouillaguet S, Gysi P, W ataha J C, Ciucchi B, Cattani M, Godin $C, M$ eyer JM. Bond strength of composite to dentin using conventional, one-step, and self-etching adhesive systems. J D ent 2001;29(1):55-61.

31. Pashley DH, Sano H, Ciucchi B, Y oshiyama M, Carvalho RM . A dhesion testing of dentin bonding agents: $A$ review. Dent $M$ ater 1995;11(2):117-25.

32. Shono $Y$, Ogawa T, Terashita M, Carvalho RM, Pashley EL, Pashley DH. Regional measurement of resin-dentin bonding as an array. J Dent Res 1999;78(2):699-705.

33. Osorio R, Ceballos L, T ay F, C abrerizo-V ilchez M A, Toledano $M$. Effect of sodium hypochlorite on dentin bonding with a polyalkenoic acid-containing adhesive system. J Biomed $M$ ater Res B: A ppl Biomater 2002;60(2):316-24.

\section{ABOUT THE AUTHORS}

\section{Bruna Uglik Garbui}

Department of O perative Dentistry, School of Dentistry, University of Sao Paulo, B razil

\section{Sergio Brossi Botta}

Department of O perative Dentistry, School of Dentistry, University of Sao Paulo, B razil

\section{Andre Figueiredo Reis}

Department of Restorative Dentistry, Guarulhos University Guarulhos, Sao Paulo, B razil

\section{Adriana Bona Matos (Corresponding Author)}

Department of O perative Dentistry, School of Dentistry, University of Sao Paulo, Brazil, e-mail: bona@usp.br 